\title{
LAS ENFERMEDADES DE BABILONIA: UN DESAFÍO PARA LOS HIJOS DE DIOS
}

Erik Jiménez Milla erikjimenez@teologia.edu.pe Universidad Peruana Unión

El presente artículo pretende mostrar el panorama sombrio hacia donde ha conducido la desobediencia a Dios liderada, a través de los años, por Babilonia. Como se percibe en la presente investigación, hay una relación entre Babilonia y lo inmundo. El no consumir nada inmundo es uno de los aspectos que diferenció al pueblo de Dios de los otros pueblos, especialmente con Egipto y Babilonia. Las diferencias de este aspecto permitirian, a pesar de vivir en una ciudad, al pueblo de Dios vivir con sanidad. Según Deuteronomio 28:1-14, la obediencia a estos preceptos y estatutos permitirian vivir como cabeza y no cola (v. 13) y crear una comunidad sana que influencie al mundo con un testimonio de la verdad de Dios. En este sentido, de amenaza constante, Elena de White escribió que los hijos de Dios no deben vivir en las tinieblas sino en la luz. El presente artículo presenta la hipótesis que, para que se pueda cumplir el objetivo de salud, es necesario revisar los mandatos bíblicos y las recomendaciones inspiradas por Dios a Elena G. de White. Se cree que si los hijos de Dios guardaran los mandatos, preceptos y estatutos, servirian en forma leal al cometido de hacer una obra médica-misionera más amplia.

Palabras clave: Reforma prosalud, enfermedad, profecias 


\title{
BABYLON DISEASES: A CHALLENGE FOR THE GOD'S CHILDREN
}

\begin{abstract}
This article aims to show the gloomy where which has led the disobedience to God led over the years by Babylon. As perceived in this research, there is a relationship between Babylon and unclean. He did not eat anything unclean, it is one of the aspects that distinguished the people of God with other peoples, especially with Egypt and Babylon. The differences in this respect would, despite living in a city, God's people live with health. According to Deuteronomy 28: 1-14, obedience to these precepts and statutes would live as head and not the tail (v. 13) and create a healthy community that influences the world with a witness to the truth of God. In this sense of constant threat, Ellen White wrote that God's children should not live in darkness but in the light. This article presents the hypothesis that it can meet the goal of health, it is necessary to review the Biblical mandates and recommendations inspired by Ellen White. It is believed that if the children of God saved, the commands, decrees and laws, dutifully serve on the task of making a broader medical missionary work.
\end{abstract}

Keywords: Health reform, disease, prophecy 


\section{Introducción}

El presente apéndice pretende mostrar el panorama sombrío hacia donde ha conducido la desobediencia a Dios liderada, a través de los años, por Babilonia. Como se percibe en la presente investigación, hay una relación entre Babilonia y lo inmundo. Apocalipsis 16:13-14 expresa que de la boca de este triunvirato satánico proceden espíritus inmundos semejante a ranas. Las ranas, como animales inmundos, representan aquí la impureza y la inmundicia. ${ }^{1}$

El no consumir nada inmundo es uno de los aspectos que diferenció al pueblo de Dios con los otros pueblos, especialmente con Egipto y Babilonia. Los hijos de Dios, desde los antediluvianos (Noé), podían diferenciar entre lo que es limpio y lo que es inmundo. Allí entra la declaración de Pedro, como buen judío, después de vivir tres años y medio con Jesús,

${ }^{1}$ Ángel Manuel Rodríguez, "Concluding Essay: God's End-Time Remnant and the Christian Church", en Toward a Theology of the Remnant, ed. Ángel Manuel Rodríguez (Silver Spring, MD: Biblical Research Institute, 2009), 499. dijo: "Señor, no, ninguna cosa común o inmunda he comido jamás" (Hch 10:14). Un judío jamás ha comido cosa inmunda.

Las diferencias de este aspecto permitirían, a pesar de vivir en una ciudad, al pueblo de Dios vivir con sanidad. Según Deuteronomio 28:1-14, la obediencia a estos preceptos y estatutos permitirían vivir como cabeza y no como cola (v. 13) y crear una comunidad sana que influencie al mundo con un testimonio de la verdad de Dios. La salud es un aspecto importante para cada hijo de Dios y fue así para los israelitas, porque Dios les mostró que las consecuencias de la desobediencia, en estos aspectos, traerían maldiciones y enfermedades (Dt 28:15-68). Específicamente los versículos 5862 del capítulo 28, del quinto libro del Pentateuco, expresan esta realidad:

Si no cuidas de poner en práctica todas las palabras de esta ley que están escritas en este libro, temiendo este nombre glorioso y temible, el Señor tu Dios, entonces el Señor hará horribles tus plagas y las plagas de tus descendientes, 
plagas severas y duraderas, y enfermedades perniciosas y crónicas. Y traerá de nuevo sobre ti todas las enfermedades de Egipto de las cuales tenías temor, y no te dejarán. También toda enfermedad y toda plaga que no están escritas en el libro de esta ley, el Señor traerá sobre ti hasta que seas destruido. Y quedaréis pocos en número, aunque erais multitud como las estrellas del cielo; porque no obedecisteis al Señor tu Dios.

La gran ciudad Babilonia ha cosechado siempre los errores de su desobediencia. Actuando con astucia, ha logrado que todo el mundo contradiga abiertamente las advertencias de Dios para el cuidado de la salud y, como consecuencia, ha visto con satisfacción cómo los años de vida del hombre han ido disminuyendo. Pero su meta es más elevada, pretende que los hijos de Dios, al vivir en la ciudad "Babilonia", caigan en estas terribles consecuencias. En este sentido, de amenaza constante, el año 1902 White escribió que los hijos de Dios no deben vivir en las tinieblas, sino en la luz. Ella escribe:

"Hemos llegado a un tiempo en el cual cada miembro de la Iglesia debe hacer obra misionera médica. Este mundo se parece a un hospital lleno de víctimas de enfermedades físicas y espirituales. Por todas partes, hay gente que muere por carecer del conocimiento de las verdades que nos han sido confiadas. Es necesario que los miembros de la Iglesia despierten y comprendan su responsabilidad en cuanto a dar a conocer estas verdades. Los que han sido alumbrados por la verdad deben ser porta luces para el mundo. En el tiempo actual, ocultar nuestra luz sería una gravísima falta. El mensaje, que Dios dirige a su pueblo hoy, es este: 'Levántate, resplandece; porque ha venido tu lumbre, y la gloria de Jehová ha nacido sobre ti' (Is 60:1). Por todas partes, se ven personas que han tenido mucha luz y conocimiento, pero eligieron voluntariamente el mal antes que el bien. No tratan de reformarse, y empeoran de día en día. Mas los hijos de Dios no deben vivir en las tinieblas. Como reformadores, deben andar en la luz". 2

La profundidad de esta declaración descansa en el gran desafío para quienes fue escrita. Se pue-

${ }^{2}$ Elena G. White, Joyas de los testimonios, (Buenos Aires: Editorial Casa Editora Sudamericana, 1995), 102 
de hacer obra médico-misionera siempre y cuando primero haya sanidad. Este apéndice presenta la hipótesis que para que se pueda cumplir el objetivo de salud, es necesario revisar los mandatos bíblicos y las recomendaciones inspiradas por Elena de White. Se cree que si los hijos de Dios guardaran los mandatos, preceptos y estatutos, servirían en forma leal al cometido de hacer una obra médica-misionera más amplia.

En esta propuesta se revisarán los planteamientos bíblicos de Deuteronomio y otras partes correlacionarlos con las recomendaciones de Elena de White. Se espera que la lectura fácil de esta investigación se profundice en la puesta en práctica de las recomendaciones encontradas.

\section{Deuteronomio y las bendiciones de la obediencia a Dios}

En primer lugar, es definitivo que los capítulos 4 al 8, del libro de Deuteronomio, contienen las bendiciones de la obediencia a

Dios. Es la misma White, que en repetidas oportunidades, pide leer con mucho cuidado el libro de Deuteronomio, sobre todo en el contexto escatológico, ella escribe:

Le pido que estudie del capítulo cuarto al octavo de Deuteronomio para que pueda entender lo que Dios requirió de su pueblo antiguo, a fin de que fuera gente santa para él. Nos estamos aproximando al día de la gran revisión final de Dios, cuando los habitantes de este mundo han de encontrarse delante del juez de toda la tierra para responder por sus hechos. Ahora estamos en el tiempo de investigación. Antes del día de la revisión de Dios, cada carácter habrá sido investigado, cada caso decidido para la eternidad. Léanse con provecho las palabras del siervo de Dios registradas en estos capítulos (Carta 112,1909$){ }^{3}$

Aunque una revisión exhaustiva de los capítulos mencionados (4-8) sería seguramente muy provechoso. Es Deuteronomio 28 que contie-

${ }^{3}$ Francis Nichol, ed., Comentario bíblico adventista, trads. Víctor Ampuero M. y Nancy Vymeister (Buenos Aires: Asociación Casa Editora Sudamericana, 1996), 1:1132; en adelante CBA. 
ne un resumen de las bendiciones a la obediencia y las maldiciones al hacer lo contrario. Este capítulo comienza advirtiendo una atención especial que, literalmente, se puede traducir como: "si ciertamente oyeres". El hebreo usa la construcción más enfática posible, invitando a considerar el asunto con toda seriedad (véase Ex 23:22). ${ }^{4}$ Pareciera decir que el asunto está en las manos de los que escuchan y, como consecuencia, algunos tomarán la decisión, mientras que otros no.

Este capítulo repasa las bendiciones del pacto, las cuales pueden ser divididas en tres grupos: bendición de la tierra y personas (vv. 3-5), victoria contra los enemigos (v. 7) y la exaltación de Israel sobre sus enemigos $(1,9,10$, 13). ${ }^{5}$ El resultado de la obediencia son bendiciones, las cuales mayormente traen el beneficio humano, especialmente en una calidad de vida y salud. Por esa razón se pide no aliarse con las costumbres de

\section{${ }^{4}$ Ibíd., 1:1064.}

${ }^{5}$ Daniel Carro, José Tomás Poe, Rubén O. Zorzoli, edit., Comentario bíblico Mundo Hispano Levítico, Números, y Deuteronomio (El Paso, TX: Editorial Mundo Hispano, 1997), 511. En adelante CBMHLND. los que no temen a Dios, es decir con Babilonia.

"Los principios presentados, en el libro de Deuteronomio para la instrucción de Israel, deben ser seguidos por el pueblo de Dios hasta el fin del tiempo. La verdadera prosperidad depende de que continuemos fieles a nuestro pacto con Dios. Nunca podemos correr el riesgo de sacrificar los principios aliándonos con los que no le temen... Existe un peligro constante de que los que profesan ser cristianos lleguen a pensar que, a fin de ejercer influencia sobre los mundanos, deben conformarse en cierta medida al mundo. Sin embargo, aunque una conducta tal parezca ofrecer grandes ventajas, acaba siempre en pérdida espiritual. El pueblo de Dios debe precaverse estrictamente contra toda influencia sutil que procure infiltrarse por medio de los halagos provenientes de los enemigos de la verdad. Sus miembros son peregrinos y advenedizos en este mundo, y recorren una senda en la cual les acechan peligros. No deben prestar atención a los subterfugios ingeniosos e incentivos seductores destinados a desviarlos de su fidelidad". ${ }^{6}$

${ }^{6}$ Elena G. de White, Profetas y reyes, (Nampa, ID: Pacific Press Publishing As- 
"Jeremías llamó su atención repetidas veces a los consejos dados en Deuteronomio. Más que cualquier otro de los profetas, recalcó las enseñanzas de la ley mosaica, y demostró cómo esas enseñanzas podían reportar las más altas bendiciones espirituales a la nación y a todo corazón individual. Suplicaba: "Preguntad por las sendas antiguas, cuál sea el buen camino, y andad por él, y hallaréis descanso para vuestra alma". (Jer 6:16).?

Las bendiciones de Deuteronomio 28 reflejan varios aspectos. Los versículos 3-6 reflejan la situación económica del pueblo. Israel las bendiciones son presentadas como abundancia de cosecha y rebaño. Si Israel obedece las leyes de Jehová, el pueblo será bendecido en la ciudad y en el campo (v. 3). Por su obediencia, a la Palabra de Dios, Israel iba a experimentar la fertilidad de los hombres y mujeres, de la tierra y de los animales (v. 4). La abundancia del campo se traduce en la abundancia de la canasta y en la abundancia de la comida (v. 6). ${ }^{8}$

sociation, 1957), 302.

'Ibíd.

${ }^{8}$ Carro, 511.
Los versículos 7-14 elaboran, con más detalles, las diez promesas de bendiciones. En 3-6, la promesa de protección y seguridad vendría de tres maneras: en primer lugar, en la victoria de Israel sobre sus enemigos (v. 7); segundo lugar, la protección de Israel vendría en forma de poder económico: Tú darás prestado a muchas naciones, pero tú no pedirás prestado (28:12); y tercero, la seguridad de la nación vendría en forma de la exaltación de Israel sobre las naciones: Israel será cabeza, no cola (v. 13). ${ }^{9}$ ¿Puede un individuo ser cabeza cuando está muy enfermo, no de enfermedades infectocontagiosas, sino de enfermedades degenerativas, en donde el médico reprende tu falta de seriedad?

La bendición del campo (v. 4) vendría en la abundancia de los graneros (v. 8), en la fertilidad del campo, de los animales y en la concepción de hijos por las mujeres israelitas (v. 11) y en la certeza de abundantes lluvias para regar el suelo (v. 12a). ${ }^{10}$

${ }^{9}$ Ibíd.

${ }^{10}$ Carro, 511. 
Sin embargo, la bendición más especial del pacto sería la posición de honor que Israel gozaría entre las naciones. Por ser obediente a las leyes y a los mandatos del pacto, Israel sería establecido como un pueblo santo, un pueblo que pertenecía a Jehová (v. 9). Además, por causa de su relación especial con Jehová, las demás naciones reconocerían que Israel era un pueblo especial y lo mirarían con respeto y temor. ${ }^{11}$

Para alcanzar esta posición exaltada entre las naciones y para recibir la bendición de la fertilidad de la tierra, de los animales y del pueblo, Israel no podía desviarse del camino que Dios había preparado. La conclusión de esta sección (v. 14) es clara y específica. Israel no podía apartarse de las palabras que Jehová había ordenado por medio de Moisés. Además, no podía adorar a los dioses cananeos ni procurar su protección ni la fertilidad de la tierra y de los animales en los dioses de piedra y madera. Israel no necesitaba usar ritos supersticiosos para sobrevi-

${ }^{11}$ Ibíd., 512. vir. Jehová podía dar a Israel todo lo que la nación necesitaba para vivir una vida feliz y próspera en la tierra que él les iba dar. ${ }^{12}$

\section{Deuteronomio y las maldiciones de la desobediencia a Dios}

Sin embargo, las maldiciones y enfermedades que describe el mismo libro pentateucal abarcan la realidad de un mundo que hizo caso omiso y se entregó a la desobediencia y muerte. Gran parte de los versículos de Deuteronomio 28 describen las maldiciones que vendrán: "Pero sucederá que si no obedeces al Señor tu Dios, guardando todos sus mandamientos y estatutos que te ordeno hoy, vendrán sobre ti todas estas maldiciones y te alcanzarán" (v. 15). Antes de mencionar la lista de enfermedades, primero aparecen las posibles maldiciones que vendrían como resultado de la desobediencia.

La primera dice: "Maldito serás en la ciudad" (v. 16), es decir, el vivir en las "grandes ciudades" traerán

${ }^{12}$ Ibíd. 
consecuencias muy serias, considerando que el primero que construye una ciudad fue Caín y que no era el plan original de Dios.

Sigue diciendo "y maldito serás en el campo" (v. 16, u.p), involucra que aun en los lugares lejanos serán invadidos por un afán babilónico de riqueza y deleite y, como consecuencias, habrá enfermedades y dolor. El versículo 17 dice: "Malditas serán tu canasta y tu artesa", lo que implica que todo lo que llevas a tu casa para comer tendrá problemas, traerán los resultados de una Babilonia que vive para el dinero y no para el bienestar humano. Como consecuencia de esto, el versículo 18 dice: "Maldito el fruto de tu vientre y el producto (lit. fruto) de tu suelo, el aumento de tu ganado y las crías de tu rebaño". Esto enlaza que los resultados se acumulan en el tiempo. Los abusos traerían como resultado en generaciones venideras, trastornos y complicaciones más severas: hijos con males de origen genético, y tierras maldecidas para una producción sana.

Los siguientes versículos siguen aludiendo a Babilonia, en especial el versículo 20, que explica la realidad de su mismo significado. Dice: "Enviará el Señor sobre ti maldición, confusión y censura en todo lo que emprendas, hasta que seas destruido y hasta que perezcas rápidamente, a causa de la maldad de tus hechos, porque me has abandonado". La palabra confusión, significado ampliado para Babilonia, podría implicar que en las ciudades se llegaría a vivir con vendas en los ojos porque, a pesar de sus males, no encontrarían la solución, porque la salida los llevaría a la obediencia a Dios la cual es contraria a los planes de Babilonia.

La lista de maldiciones es más detallada que la lista de bendiciones. Esta descripción detallada de las maldiciones sigue los tratados políticos del antiguo Oriente, los cuales generalmente incluían más maldiciones que bendiciones. Esta lista también refleja la severa penalidad que la violación del pacto trae sobre la nación. Pero todas las maldiciones tienen un solo propósito: el llevar a Israel al arrepentimiento y motivar a la nación a volver a Jehová (véase 30:1-5). ${ }^{13}$

${ }^{13}$ Ibíd., 513. 
Estas enfermedades devastadoras fueron la experiencia común de todas las culturas antiguas. Israel había experimentado en vivo cuando Dios hirió a los egipcios con las diversas plagas (Ex 9:8-12). Pero ahora la advertencia es clara, la enfermedad podría atacar a Israel. Literalmente "pestilencias se aferran a" ellos. Es significativo que más referencias a enfermedades se refieren a ellos como las enfermedades "de Egipto" (vv. 27, 60)..$^{14}$

Indudablemente Dios utiliza la relación de enfermedades físicas en la historia de Israel para permitirse ejecutar juicio (2 S 24:13-15; 1 R 8:37; Ez 5:12; Am 4:10). El versículo 22 proyecta enfermedades para los cultivos. Por lo tanto, el juicio iba a ser integral, golpeando gente y plantas por igual. Los seres humanos y la tierra se convertirían en enfermos. ${ }^{15}$

Es entonces que Deuteronomio comienza a describir las enfermedades, como parte de una

${ }^{14}$ Gary Harlan Hall, Deuteronomy, en The College Press NIV Commentary, (Joplin, MO: College Press Pub., 2000), 418. ${ }^{15}$ Ibíd. maldición que describe así el v. 21: "El Señor hará que la peste se te pegue hasta que te haya consumido de sobre la tierra a donde vas a entrar para poseerla". La lista empieza así: "Te herirá el Señor de tisis (TBC), de fiebre, de inflamación (dolor de cabeza) y de gran ardor (gastritis), con la espada (también se traduce como sequía, estreñimiento), con tizón y con añublo (del heb. yeraqon, que quiere decir "palidez"); y te perseguirán hasta que perezcas". Esta parte final explica las declaraciones constantes que se escucha en la Babilonia moderna: "ya no podemos hacer nada por usted".

El vivir, en una gran ciudad, implicaría también la contaminación ambiental por metales pesados, según el v. 23, "Y el cielo que está encima de tu cabeza será de bronce, y la tierra que está debajo de ti, de hierro". Describe uno de los problemas más álgidos desde la creación de las grandes metrópolis. A lado de ello, se menciona un mal como consecuencia de vivir en grandes ciudades, la depresión, el v. 25 dice: "El Señor hará que seas derrotado delante de tus enemigos; saldrás contra ellos por 
un camino, pero huirás por siete caminos delante de ellos".

De allí viene lo más trágico, aquello que Babilonia originó con su desobediencia, el cáncer, el v. 27 dice: "Te herirá el Señor con los furúnculos (heridas) de Egipto y con tumores (cáncer), sarna y comezón, de los que no podrás ser sanado". Esto explica que el problema que hoy enfrenta Babilonia, lo vivieron en forma inicial, las grandes ciudades rebeldes, que osaron demostrar que podían vivir sin la dirección de Dios. El punto de inicial, de referencia, es que la primera ciudad fue creada por Caín en abierta rebeldía a Dios (Gn 4:17). Como resultado de esto la voluntad de Dios, de vivir en el campo y disfrutar de la naturaleza y salud abundante, quedaría relegada y las consecuencias no se harían esperar en todas las áreas de la vida del hombre. ${ }^{16}$

16“Esto sugiere que Caín quizá no tuviera mucha confianza en la protección que Dios le aseguraba. También es posible que su intento de fundar una ciudad puede haber sido dictado por un deseo de desafiar la maldición que lo condenaba a una vida errante. Es digno de notarse que la primera "ciudad"
La lista va en aumento, el v. 28: "Te herirá el Señor con locura (esquizofrenia), con ceguera y con turbación de corazón”, el v. 29 “y andarás a tientas a mediodía como el ciego anda a tientas en la oscuridad y no serás prosperado en tus caminos; más bien serás oprimido y robado continuamente, sin que nadie te salve". El cambio del carácter del ser humano produciría la violencia y la crueldad entre ellos mismos.

Los versículos posteriores describen el surgimiento de otros pecados que atacan la misma familia, el v. 30 dice: "Te desposarás con una mujer, pero otro hombre se acostará con ella; edificarás una casa,

del mundo fue fundada por el primer asesino del mundo, un individuo perversamente impenitente cuya vida, plenamente dedicada al mal y sin ninguna esperanza, transcurrió desafiando a Dios. Así se torció el plan de Dios de que el hombre viviera en medio de la naturaleza y contemplara en ella el poder y la majestad del Creador. Muchos males de hoy en día son el resultado directo de un amontonamiento antinatural de seres humanos en las grandes ciudades, donde predominan los peores instintos del hombre y donde florecen vicios de toda clase". Nichol, ed., CBA, 1:254. 
pero no habitarás en ella; plantarás una viña, pero no aprovecharás su fruto”. Adulterio, abandono y una vida sin sentido acompañan a la degradación humana.

Los siguientes versículos describen algunos problemas atañidos con la parte emocional relacionados a la familia. El v. 35 describe algunas enfermedades que se derivan de estos problemas emocionales, en la soledad, "Te herirá el Señor en las rodillas (artrosis) y en las piernas con pústulas malignas de las que no podrás ser sanado, desde la planta de tu pie hasta la coronilla".

Es minuciosa la lista de enfermedades que describe Deuteronomio 28, aunque pareciera que Dios es el que manda la enfermedad o dolencia, se debe entender que es la consecuencia a la desobediencia la que nos saca de la protección de las leyes y principios de Dios. Es por ello que, al lado de cada enfermedad, la inmoralidad está presente, entonces es comprensible que Dios no puede obrar "milagros" cuando hay quebrantamiento de los principios de salud del hombre.

\section{La obesidad y Babilonia}

Una de las enfermedades más comunes, en el mundo y por consiguiente la que trae más muerte en la humanidad, tienen su relación con las enfermedades cardiovasculares. La acumulación de grasa en el cuerpo traería sus consecuencias.

Deuteronomio 32:15 dice: "Pero engordó Jesurún, y tiró coces. Engordaste, te cubriste de grasa; entonces abandonaste al Dios que te hizo, y menospreciaste a la Roca de tu Salvación”. El nombre Jesurún aparece aquí, en 33:5, 26 y en Isaías 44:2, como una forma poética para designar a Israel, en hebreo significa "justo". Este nombre especial de Israel enfatiza que Israel es un pueblo especial, un pueblo santo, separado para el servicio y adoración de Jehová. ${ }^{17}$ Pero a pesar de ello, la provisión de Dios en el desierto y de su bendición en la tierra prometida, Israel, se engordó y como un animal no domesticado, dio coces. ${ }^{18}$ Coces es la costumbre

${ }^{17}$ Carro, 543.

${ }^{18}$ Ibíd. 
de un animal de patear con sus patas traseras, lo que involucraba la descripción de un animal bastante temperamental.

En esas condiciones de salud, Israel menospreció o "se burló de" (literalmente, "trató como necio") Jehová. El mismo verbo se traduce como: actuar "neciamente" ( $\mathrm{Pr}$ 30:32), "pondré como estiércol" (Nah 3:6), "deshonra" (Mi 7:6). El adjetivo de la misma raíz se traduce "loco" (Dt 32:6), "insensato" (Dt 32:21; Pr 17:21; Jer 17:11; Ez 13:3), "necio" (Sal 14:1; 53:1; Pr 17:7; 30:22). ${ }^{19}$ La ciencia actualmente dice que todo obeso es un paciente psiquiátrico. ${ }^{20}$

${ }^{19}$ Nichol, ed., CBA, 1:1082.

${ }^{20} \mathrm{El}$ neurotransmisor dopamina parece mostrar mayores evidencias de un rol causal en la obesidad, habiéndose encontrado una asociación entre la presencia del alelo A1 del Gen DRD2 y la obesidad. En presencia de tres factores fenotípicos (historia familiar de obesidad, edad de comienzo y preferencias por alimentos) el alelo A1 explicaría un $86,4 \%$ de la varianza en la presentación de la enfermedad. La presencia de este alelo se asocia con un número reducido de receptores de dopamina D2, sugiriendo que los pacientes obesos usarían el comer alimentos como una forma de elevar los niveles de dopamina cerebral a niveles más aceptables. Llama la atención
Posteriormente, Job 15:27-32 explica que no durará, su tiempo será acortado, el texto explica: "Porque la gordura cubrió su rostro, e hizo pliegues sobre su cintura" (v. 27), "Él será cortado antes de su tiempo"(v. 32). Jeremías 5:28 clarifica un poco más el problema de la gordura "se engordaron y se pusieron lustrosos, y sobrepasaron los hechos del malo...". La gordura es una figura de la vida sibarítica e intemperante del impío (véase Sal 73:7). ${ }^{21}$ Las expresión se pusieron lustrosos quizá se refiera a la tersura de su piel que refleja en problemas de exceso de grasa en la cara. ${ }^{22}$

Pareciera que todos estos textos apuntan que el inicio de todas las enfermedades tiene que ver con la alimentación incorrecta. Cuando

que las conductas del obeso son visiblemente similares a la de los dependientes de sustancias y que muchos de sus tratamientos tienen principios en común con las adicciones. Daniel Seijas Buschiazzo y Christian Feuchtmann Sáez, "Obesidad: Factores psiquiátricos y psicológicos", $\mathrm{BO}$ letín Escuela de Medicina 26:38-41 (1997), bajo Pontificia Universidad Católica de Chile. http://escuela.med.puc.cl/paginas/ publicaciones/boletin/html/obesidad/ obesidad10.html (consultado: 20 de junio, 2014).

${ }^{21}$ Ibíd., 3:543.

${ }^{22}$ Ibíd. 
se desobedece a Dios, hay una consecuencia que enfrentar. Aunque los textos leídos en Deuteronomio parecieran expresar que Dios está listo a castigar con enfermedades y plagas, pero Dios no es así. Lo real es que Dios no castiga, sino que el hombre cosecha las consecuencias de su desobediencia. Si Dios curara toda dolencia con un toque mágico, como lo expresan actualmente las hijas de ramera Babilonia, el ser humano no tendría reglas y principios para el cuidado de la salud. Entonces, los milagros serían más necesarios de lo que hoy se ve. Entonces, el pecado se perpetuaría y la maldad no tendría fin. La maldición frente a la desobediencia es que Dios no puede actuar frente al descuido de sus principios.

\section{Deuteronomio 14 y la alimentación abominable}

El versículo 3, de este capítulo, dice que un hijo de Dios no debía comer nada abominable. Esta referencia es ligada a aquellas cosas "abominables" por razones sanitarias, higiénicas o de otra índole
(1 Ti 4:4; Ro 14:14), indicando, a partir de aquí, que los principios cristianos deben regular el comer y el beber.

Los principios expuestos, tanto en Deuteronomio 14 y Levíti$\cos 11$, fueron establecidos por Dios para que, los que le aman y escogen servirle, no consuman los alimentos de origen animal que podrían dañar sus cuerpos. Es basado en estos estatutos que el cristiano propone en su corazón no contaminar el "templo de Dios" (1 Co 3:17) sino hacer "todo para la gloria de Dios” (1 Co 10:31). Para tal persona, los principios fundamentales que se bosquejan, en estos textos, serán una orientación suficiente. ${ }^{23}$

En Levítico 11 la palabra "inmundo" es entendido por los judíos como "abominación", shaqats (vv. 11, 13, 43). De la misma raíz es el verbo abominar en Deuteronomio 7:26 y Salmo 22:24. Los animales que aquí se enumeran como "inmundos" no son aptos para la alimentación humana y, como ya se mencionó, son conocidos como tales des-

${ }^{23} I$ bíd., 1:766. 
de el tiempo antediluviano ( $\mathrm{Gn}$ 9:3). ${ }^{24}$ Aún hoy los judíos toman en cuenta estas recomendaciones dadas hace unos 3500 años atrás, y los resultados han sido más que beneficiosos.

La condición física, de los judíos, da testimonio de que estas reglas no son obsoletas ni han perdido su vigencia, ellos entendieron que su propósito era el de producir un pueblo notablemente libre de muchas de las enfermedades. Por ello, a pesar de las persecuciones y las penalidades sufridas por los judíos, mayores que las experimentadas por cualquier otra nación sobre la faz de la tierra, y por períodos más largos, en general los judíos son una raza vigorosa. Al menos en parte, este hecho se explica por su obediencia a las leyes sobre alimentación presentadas por Dios en Levíticos $11 .^{25}$

\section{Principios bíblicos para el consumo de carne}

Si bien es cierto, la Biblia justifica el consumo de carne, también

${ }^{24}$ Ibíd.

${ }^{25}$ Ibíd., 1:769. es real que da las pautas necesarias para que este produzca el menor daño. El primer consejo está en evitar el consumo de las carnes inmundas o abominables. Basta con repasar la lista de Levíticos 11. Pero de los animales limpios tenían que tener cuidado.

Elena de White explica:

"Al establecerse en Canaán, se permitió a los israelitas que consumieran alimento de origen animal, pero bajo prudentes restricciones encaminadas a mitigar los malos resultados. El uso de la carne de cerdo quedaba prohibido, como también el de la de otros animales, de ciertas aves y de ciertos peces, declarados inmundos. De los animales declarados comestibles, la grasa y la sangre quedaban absolutamente proscritas. Solo podían consumirse las reses sanas. Ningún animal desgarrado, mortecino o que no hubiera sido cuidadosamente desangrado, podía servir de alimento". ${ }^{26}$

La prohibición de comer carne de un animal "mortecino o

${ }^{26}$ Elena G. de White, Consejos sobre el régimen alimenticio (Miami, FL: Asociación Publicadora Interamericana, 1975), 447. 
despedazado por fiera” sin duda se debía a que, en tales casos, casi toda la sangre quedaba en el cadáver, sin ser drenada en la forma debida o que haya muerto por una enfermedad. ${ }^{27}$ El testimonio de Ezequiel es bastante positivo, porque los fieles tenían una obediencia absoluta en este aspecto: "Y yo dije: ¡Ah, Señor Dios! He aquí, nunca me he contaminado; porque desde mi juventud hasta ahora nunca he comido animal muerto o despedazado (mortecino), ni jamás ha entrado en mi boca carne inmunda".

Las declaraciones de Éxodo 12, aunque pareciera no tener relación con el tema, es la que pareciera establecer los principios de Salud en cuanto al consumo de carne. La pascua lleva a todo judío a mirar el asunto de otra

${ }^{27}$ Nichol, ed., $C B A, 1: 768$. Literalmente, "cualquier res muerta", es decir, de un animal que muere por sí mismo, por enfermedad o por otra causa. Esta prohibición es una repetición de $\mathrm{Lv}$ 11:39, 40 (véase también Lv 17:15). La palabra hebrea viene del verbo "hundirse", "languidecer", "desmayar y desvanecer". Se traduce también "desfallecer" (Ex 18:18), "secarse" (Sal 37:2), "disolverse" (Is 34:4), "te pondré como estiércol" (Nah 3:6). Ibíd., 1:1015. manera. Principios que, posteriormente, llevaron a Daniel y a sus tres compañeros a no comer de la mesa del rey.

El primer principio se encuentra en la expresión del v. 5, que dice: "El cordero será un macho sin defecto". La expresión, sin defecto, determina que, aparte de no tener un defecto físico, como el ser "ciego" o "cojo", el animal debería ser sano y no estar "enfermo". ${ }^{28} \mathrm{~A}$ partir de allí, un israelita no podía comer carne sino sabía la procedencia del animal y la forma cómo este había sido sacrificado. A este proceso se lo llama actualmente Kosher. ${ }^{29}$ Son muchas las reglas pero lo esencial es el principio, el animal tiene que ser sin enfermedad, en otras palabras, estar sano. Si se hace eso, se tendrá menos posibilidades de enfermedades derivadas de este tipo de carne. Deuteronomio 14:21 describe el principio: "Ninguna cosa mortecina comeréis", también es tradu-

\footnotetext{
${ }^{28}$ Ibíd., 1:561

${ }^{29}$ Jabad.org.ar, "Todo sobre la carne $y$ aves Kosher" http://www.jabad.org.ar/ biblioteca/kasher-biblioteca/carne-kasher/todo-sobre-la-carne-y-aves-kosher/ (consultado: 15 de junio, 2014).
} 
cida como "No comeréis ningún animal que se muera por sí”. La palabra "mortecina" se aplica a un animal que muere por sí mismo, por enfermedad o por otra causa. ${ }^{30}$ White lo explica:

"La carne no fue nunca el mejor alimento; pero su uso es hoy día doblemente inconveniente, ya que el número de los casos de enfermedad aumenta cada vez más entre los animales. Los que comen carne y sus derivados no saben lo que ingieren. Muchas veces si hubieran visto los animales vivos y conocieran la calidad de su carne, la rechazarían con repugnancia. Continuamente sucede que la gente come carne llena de gérmenes de tuberculosis y cáncer. Así se propagan estas enfermedades y otras también graves". ${ }^{31}$

"Los animales están enfermos y, al participar de su carne, implan-

${ }^{30} \mathrm{La}$ palabra hebrea viene del verbo "hundirse", "languidecer", "desmayar y desvanecer". Se traduce también "desfallecer" (Ex 18:18), "secarse" (Sal 37:2), "disolverse" (Is 34:4), "te pondré como estiércol" (Nah 3:6). Nichol, ed., CBA, 5:1015.

${ }^{31}$ Elena G. de White, Ministerio de curación (Nampa, ID: Pacific Press Publishing Association, 1959), 241. tamos la semilla de la enfermedad en nuestros propios tejidos y en nuestra sangre. Luego, cuando estamos expuestos a cambios en una atmósfera palúdica, somos más sensibles a los mismos; también cuando estamos expuestos a epidemias y a enfermedades contagiosas, el organismo no se halla en buena condición para resistir la enfermedad. El peligro de contraer una enfermedad aumenta diez veces al comer carne". 32

Una recomendación, para aquellos que no quieran dejar de consumir carne, sería de salir al campo y, de esa manera, conocer la procedencia del animal. Se podría mirar las condiciones naturales en que fue criado y ver que esté en perfecto estado de salud. Al hacer esto, ocurrirá un fenómeno, la carne solo se podría comer en ocasiones especiales, como lo ha sido siempre en los que viven en el campo. El consumo excesivo de carne es consecuencia de vivir en la ciudad, en donde constantemente se repite el drama:

"El hijo mayor creía que no podía comer una sola comida si

${ }^{32}$ White, Consejos sobre el régimen alimenticio, 461-2. 
no había carne y se manifestaba muy disgustado, y llegaba hasta la falta de respeto si no se le servía. La madre lo había mimado en sus gustos, hasta el punto de haber llegado a ser una esclava de sus caprichos. No le habían enseñado a trabajar y pasaba su tiempo leyendo cosas inútiles o peores que inútiles. Se quejaba casi constantemente de dolor de cabeza y no le agradaban los alimentos sencillos". ${ }^{33}$

Segundo principio, no comer carne con nada que contenga levadura, el pan tenía que ser sin levadura (v. 8). El cordero asado debía comerse con panes sin levadura, pues la levadura produce fermentación, un símbolo natural de impureza y corrupción moral. ${ }^{34}$

Un tercer principio, sería el comer hierbas amargas (v. 8) para mitigar el ácido que produce la carne y que trae problemas al hígado, órgano que tiene a su cargo procesar todo lo que comemos y bebemos, así como tareas de nutrición, desdoblar substancias, transformaciones químicas y muchas cosas más. El hígado se ayuda con hierbas amargas después de las comidas. El

${ }^{33}$ Ibíd., 285.

${ }^{34}$ Nichol, ed., $C B A, 1: 563$. sabor amargo está relacionado con el hígado, la bilis es amarga, y las hierbas amargas son depuradoras del hígado. ${ }^{35}$ Una vez más se ve la sabiduría en las órdenes que dio Dios a su pueblo.

\section{Salud de los judíos: No es entendida por el mundo}

La directora del registro nacional de cáncer en Israel, Dr. Micha Barchana, ha informado recientemente, que la ya baja tasa de casos de cáncer en su país continúa reduciéndose de forma alentadora. En el año 2004, solo 152 personas murieron de cáncer de los 7,4 millones de habitantes de Israel. Comparada con Lima, de 8,4 millones entre los años 2004 y 2005, el número de registrados de muerte por cáncer fueron 13,871 , según el Instituto Nacional de Enfermedades Neoplásicas (INEN). ${ }^{36}$

${ }^{35}$ Revista Mundo Natural, "Síntomas de hígado recargado", http://www. revistamu ndonatural.com/noticia. cfm?n=471\#axzz3FZ3iWbgZ (consultado: 18 de junio, 2014).

${ }^{36}$ Departamento de epidemiología y estadística, ed., "Registro de Cáncer de Lima Metropolitana”, Instituto Nacio- 
Esto da como resultado en Israel la sensacional cifra de 0,4 fallecidos de cáncer por día. Comparativamente: en el mismo año, solo en Alemania, murieron 220.000 personas de cáncer, por consiguiente, 601 personas por día. En Austria fueron un total de 55 fallecidos de cáncer diarios y en Suiza "solo" 40. En Israel, sin embargo, ¡este valor se sitúa en un porcentaje todavía más bajo! De las estadísticas israelíes se deduce que la mayoría de las víctimas de cáncer tienen su origen en la población no judía. Con lo que la tasa de mortalidad judía es todavía más baja. ${ }^{37}$

El último dato encontrado referente al Perú, presentado por la liga contra el cáncer en el diario el Comercio, estima que unos 45,000 casos nuevos de cáncer se

nal de Enfermedades Neoplásicas, 20042005, http://www.inen.sld.pe/portal/ documentos/pdf/banners_2014/Febrero/13022014_Libro_RCLM_04_05.pdf (consultado: 25 de junio, 2014).

${ }^{37}$ Agencia judía de noticias, Cáncer: espectacularmente escaso en Israel, http:// www.prensajudia.com/shop/detallenot. asp? notid=11276 (consultado: 25 de junio, 2014). registrarán este año, y de ellos cerca de 30,000 personas no podrán recobrarse de esta enfermedad, aseguró hoy Adolfo Dammert, presidente de la Liga Contra el Cáncer en Perú. ${ }^{38}$

Miri Zil, directora general de la Asociación de la Lucha Contra el Cáncer, opinó que: "hay puntos que nos dan luz, pero el camino todavía es largo. El público debe entender que el cáncer no es un decreto del cielo. Hay que esforzarse por llevar un estilo de vida sano, una alimentación adecuada y evitar de fumar". ${ }^{39}$

La Organización Mundial de la Salud explica que, aproximadamente, un 30\% de las muertes por cáncer se deben a cinco factores de riesgo comportamentales y alimentarios: Índice de masa

38“Se registrarían más de 40 mil casos de cáncer solo en este año", El comercio http://elcomercio.pe/lima/ciudad/ se-registraran-mas-40-mil-casos-cancer-solo-este-ano-noticia-1757419 (consultado: 7 de octubre, 2104).

${ }^{39}$ Agencia judía de noticias, Cáncer: espectacularmente escaso en Israel, http:// www.prensajudia.com/shop/detallenot. asp? notid=11276 (consultado: 25 de junio, 2014). 
corporal elevado (obesidad), consumo insuficiente de frutas $y$ verduras, falta de actividad física y consumo de tabaco y alcohol. Pero el principal, una dieta malsana, y, por lo tanto, puede prevenirse. $^{40}$ Es interesante que el mundo científico reconozca que las enfermedades tienen su origen en la mala alimentación. Al entrar a un hospital que lucha contra el cáncer, se encontrará una lista de "No comas esto o aquello", pero le dicen al que ya está muriendo. Esos letreros deben salir a la calle como advertencia para los que están camino a la enfermedad. Pero quién entiende a Babilonia.

La dieta judía, aparte de ser bíblica, absteniéndose de lo inmundo o abominable, ha tenido influencia de las investigaciones modernas, ellos están dispuestos a cambios radicales, siempre que ayuden en la salud. El INEN, especializada en cáncer, advierte de los principales problemas que con-

${ }^{40}$ Organización Mundial de la Salud, Datos y cifras sobre el cáncer, Cáncer, nota descriptiva No 297, febrero de 2014, http:// www.who.int/mediacentre/factsheets/ fs297/es (consultado: 25 de junio, 2014). tienen las dietas no saludables: El consumo excesivo de sal y comidas ahumadas se asocia a cáncer de estómago; asimismo, el consumo excesivo de azúcares, grasas animales y carnes rojas se asocia a cáncer de colon. ${ }^{41}$ La alimentación, de la nación israelita, hace varios años que es sin mucha sal y bajo de azúcar, y en todo restaurante sirven abundante ensalada. ${ }^{42}$

Pero Dios no quería la ignoran-

${ }^{41}$ Departamento de epidemiología y estadística, ed., "Registro de Cáncer de Lima Metropolitana”, Instituto Nacional de Enfermedades Neoplásicas, 20042005, http://www.inen.sld.pe/portal/ documentos/pdf/banners_2014/Febrero/13022014_Libro_RCLM_04_05.pdf (consultado: 25 de junio, 2014).

${ }^{42}$ Se invitó al Cuarteto de Cuerdas del Conservatorio de Música de la Universidad Peruana Unión al cumpleaños del embajador de Israel en Lima, Perú. Entre los invitados había una suerte de autoridades, desde el rango más alto (ministros de estado, expresidentes, congresistas, etc). Después de tocar cerca de 60 minutos, el mismo embajador invitó al grupo a comer. Grande fue la decepción de los primeros que fueron al bufé. Todos los alimentos eran bajos de sal, y los que decían ser dulces, para el paladar corrompido, no tenía nada de azúcar. (Experiencia, San Isidro, 12 octubre, 2012). 
cia en este aspecto, Apocalipsis 18 habla que los mercaderes se han enriquecido a costa de Babilonia, de los deleites de sus comidas y su inmoralidad. Babilonia ha experimentado el placer del apetito, pero detrás de esto han venido sobre ella esta multitud de enfermedades descritas en Deuteronomio 28. Por eso el llamado a salir de Babilonia involucra salir de las costumbres y deleites de Babilonia, el apetito tiene que ser controlado. En muchas ciudades, mientras más sabrosa ha sido la comida, mayor incremento de la enfermedad.

\section{Diferencias entre estatutos y ordenanza, mandamientos y leyes}

La expresión "para guardar y poner por obra" marca una actitud de súplica y consideración especial para que se obedezcan los mandamientos. La palabra mandamiento puede aplicarse también para las ordenanzas entre seres humanos, sobre todo de los reyes a sus súbditos (1 R 2:43; Est 3:3; Pr 6:20; Is 36:21; Jer 35:18), también a un cuerpo de enseñanzas ( $P r$ $2: 1 ; 3: 1)$. También se refiere a la expresión a los mandamientos de Dios (1 R 13:21); frecuentemente aparece esta expresión en plural para designar el cuerpo entero de leyes divinas e instrucciones ( $\mathrm{G} n$ 26:5; Ex 16:28; Dt 6:2). ${ }^{43}$

Es así que el cumplimiento de estos mandamientos (no solo los 10 mandamientos de Éxodo 20) traerá las bendiciones, que Deuteronomio expresa de la siguiente manera: "Te pondrá Jehová por cabeza, y no por cola, y estarás encima solamente, y no estarás debajo, si obedecieres los mandamientos de Jehová tu Dios" (Dt 28:14).

Hay algunas palabras que se describen para mandamiento, "Porque Abraham obedeció mi voz y guardó mi ordenanza [mishmeret], mis mandamientos [mishwah], mis estatutos [huqqah] y mis leyes [tôrah]" (Gn 26:5). ${ }^{44}$ De estas cuatro palabras,

${ }^{43}$ Warren Baker, The Complete Word Study Dictionary: Old Testament (Chattanooga, TN: AMG Publishers, 2003), 654.

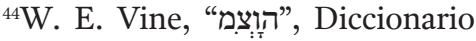
expositivo de palabras del Antiguo y del Nuevo Testamento exhaustivo (Nashville, TN: Caribe, 2001), 187. En 
la palabra que es más usada en el pentateuco, es huqqah. ${ }^{45}$ Muy poco se encuentra en los libros poéticos y en los escritos proféticos (excepto Jeremías y Ezequiel). ${ }^{46}$ Aunque es cierto que estas palabras a veces tienen varias traducciones sinónimas, lo cierto que su raíz הזקְ [huqqah] es relacionada con obligación, decreto, ley, ordenación y otros sinónimos. ${ }^{47}$

En la práctica de la escritura del pentateuco huqqah se usa en un sentido más cultural que religioso para referirse a las costum-

\section{adelante, VDEPANT.}

${ }^{45} \mathrm{El}$ vocablo juqqah tiene muchos sinónimos. A veces integra una serie de tres: "Cuídate de no olvidarte de Jehová tu Dios, dejando de guardar sus mandamientos [mishwah], sus decretos [mishpat] y sus estatutos [juqqah] que yo te mando hoy" (Dt 8:11 RVA). En otros casos, el vocablo se une a una serie de cuatro sinónimos: "Amarás, pues, a Jehová tu Dios y guardarás sus ordenanzas [mishmeret], sus estatutos [juqqah], sus decretos [mishpat] y sus mandamientos [mishwah], todos los días" (Dt 11:1; cf. Gn 26.5 con tôrah en lugar de mishpat). Ibíd, 115.

${ }^{46}$ Ibíd.

${ }^{47}$ Pedro Ortiz, V., S.J., Léxico hebreoespañol y arameo-español (Miami, FL: Sociedades Bíblicas Unidas, 2000). bres de las naciones: "No haréis como hacen en la tierra de Egipto, en la cual habéis habitado. Tampoco haréis como hacen en la tierra de $\mathrm{Ca}$ naán a la cual os llevo. No seguiréis sus costumbres" (Lv 18:3; cf. 20:23). El requerimiento de abstenerse de las prácticas paganas se debe a que se consideraban degeneradas ( $\mathrm{Lv}$ $18: 30) .{ }^{48}$

Los "estatutos" de un pueblo a veces pueden ser prácticas que son contrarias a las expectativas divinas, el profeta Miqueas explica "Porque los mandamientos de Omri se han guardado, y toda obra de la casa de Acab; y en los consejos de ellos anduvisteis, para que yo te pusiese en asolamiento, y tus moradores para burla. Llevaréis, por tanto, el oprobio de mi pueblo" (Mi 6:16). El profeta Ezequiel condenó a Judá por rechazar los "estatutos" santos de Dios: "Pero ella se obstinó contra mis decretos con mayor culpabilidad que las demás naciones, y contra mis estatutos [juqqah], más que los países que están alrededor de ella; porque desecharon mis decretos y no anduvieron según mis estatutos [juqqah]" (Ez 5:6

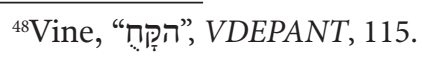


RVA). Ezequiel también desafió al pueblo de Dios a arrepentirse y volver a los "estatutos" divinos para que pudiesen vivir: "Si el impio restituye la prenda y paga lo que ha robado; si camina según los estatutos de la vida, no haciendo iniquidad, ciertamente vivirá; no morirá" (Ez 33:15 RVA).49

Babilonia encuentra deleite en implantar cosas contrarias a las establecidas en la Palabra del Señor. Tal como sucedió en Gadara, Babilonia pone en la mente corrompida de los hombres el amor al dinero por encima de todo. Lo que sucedió con el endemoniado gadareno sucede en la actualidad. Los mercaderes prefirieron mirar su ganancia económica más que la restauración de un ser humano. La influencia de Gadara continúa hoy, la carne más consumida en el mundo entero es la carne de cerdo, contradiciendo a lo establecido por Dios, sin tener en cuenta la salud de los seres humanos, el mundo actual mira lo económico más que la salud de la población. En ese contexto, el impacto eco- nómico de las grandes industrias alimentarias, hace que casi sea imposible obligar que las megas empresas (gaseosas, chocolate, alimentos industrializados, etc.) cambien, debido al sostenimiento financiero que generan en la economía mundial.

\section{Estatutos y ordenanzas para la salud en el tiempo escatológico}

Sin embargo, Dios se anticipó a todo ello, estableciendo algunas recomendaciones o "estatutos" que harían que sus hijos sean protegidos en estos últimos tiempos de todas las enfermedades. No importaría dónde vayan en el cumplimiento de la misión, o de qué cultura sean, ellos tenían que tener en cuenta estos consejos y vivirían sanos. Así como Daniel, al llegar a vivir a Babilonia, estableció un mecanismo de alimentación contrario al establecido en esta gran ciudad, ahora los Danieles modernos tienen que vivir dándole la espalda a la Babilonia escatológica.

${ }^{49}$ Ibíd. 
Una cita que puede desenmascarar este asunto y percibir las verdaderas intenciones de Satanás, se describe en la siguiente declaración que data de 1901:

"Satanás reunió a los ángeles caídos para planear alguna manera de hacer el mayor daño posible a la familia humana. Se hizo una propuesta tras otra, hasta que finalmente Satanás mismo ideó un plan. Tomaría el fruto de la vid, como también el trigo y otras cosas dadas por Dios como alimento, y las convertiría en venenos que arruinarán las facultades físicas, mentales y morales del hombre y subyugarán de tal forma los sentidos que Satanás lograse el dominio completo. Bajo la influencia del licor los hombres serían llevados a cometer crímenes de toda clase. El mundo se corrompería mediante el apetito pervertido. Haciendo que los hombres tomaran alcohol, Satanás los degradaría cada vez más (Review and Herald, 164-1901)". ${ }^{50}$

Es allí donde la pregunta toma sentido, ¿por qué un hijo del pueblo remanente se enferma igual que los demás? Quizá la respuesta

${ }^{50}$ White, La temperancia, 12. sea: "Porque no guardan los estatutos, normas y preceptos que Dios estableció al iniciar el tiempo final de la historia". Cuando Dios estableció el inicio del tiempo del fin, también tomó lugar la existencia de su Iglesia que predicaría el último mensaje. Fue así que, cuando se organizaba esta Iglesia, la Iglesia Adventista del Séptimo Día, Dios le proveyó de consejos (estatutos) que ninguna otra denominación tenía, los cuales le permitirían cumplir la comisión de ayudar al mundo como médicos misioneros en un mundo que tendría como característica final de su historia, la descripción metafórica de "hospital lleno de víctimas de enfermedades físicas y espirituales".

Por esta razón, se podría entender que la orden de salir de Babilonia es una realidad, la descripción del juicio de Babilonia en Apocalipsis 16:19, expresa que al final el llamado a "salir" de Babilonia (Ap 18:4) implicaría que los hijos de Dios deben rechazar la cultura y los valores de Babilonia. ${ }^{51}$ Esto abarca que el cristiano

${ }^{51}$ Harrington, Revelation, De Sacra Pagina Series, editado por Daniel J. Harrington, (Collegeville, MN: Liturgical 
debe estar atento a lo que perjudica las buenas costumbres del pueblo de Dios y buscar la salud total en su vida.

En este sentido una de las citas que duele mucho exponerla es aquella que advierte del resultado o las consecuencias de mantenerse con un apetito pervertido. En 1909 ella da una declaración desafiante, relacionando un texto de Isaías como un intento desesperado en la búsqueda de una respuesta favorable de sus oyentes. Esta cita dice:

"Si después de habérsele dado tanta luz, el pueblo de Dios continúa fomentando sus malas costumbres y sigue complaciendo sus apetitos en oposición a la reforma, sufrirá las consecuencias inevitables de la transgresión. Dios no salvará milagrosamente de las consecuencias de sus faltas a aquellos que están resueltos a satisfacer a toda costa su apetito pervertido. Les advirtió: 'En dolor seréis sepultados' (Is 50:11)”. ${ }^{52}$

Cuando alguien enferma es muy importante la oración de la

Press, 1993), 177.

${ }^{52}$ White, Joya de los testimonios, $3: 364$.
Iglesia, sin embargo, esta declaración es clara para no caer en un error, solo se puede reclamar un milagro del Señor si se aprendió a controlar el apetito pervertido. Pueden orar diez personas, y la persona seguirá muriendo. Pueden orar mil personas, diez mil personas, todos los habitantes de la tierra y del universo, pero si la persona no modifica su apetito pervertido, "en dolor será sepultada".

\section{Recomendaciones o Estatutos sobre Salud, de Elena de White}

Hay muchas recomendaciones que no necesariamente vienen como un mandato o estatuto, pero que si se mira con detenimiento, están establecidas como los consejos bíblicos que determinaron el desarrollo de la salud del pueblo de Dios. En realidad hay una cantidad de detalles, pero se considerarán algunos que tienen una importancia actual, en relación a las enfermedades más comunes que sufre la Iglesia. 


\section{No comer azúcar}

En 1870 hay una declaración que paraliza el caminar babilónico de un cristiano normal: "Cualquier cosa que estorba el movimiento activo del organismo, afecta muy directamente el cerebro. Y por la luz que me ha sido dada, sé que el azúcar, cuando se usa copiosamente, es más perjudicial que la carne". ${ }^{53}$ Interesante que ella pone el azúcar en el nivel máximo de peligrosidad. Hoy en día bastaría poner la palabra "azúcar, sus efectos" en los buscadores de internet, y se podría entender que se reconoce como el enemigo número uno de la salud.

En el manuscrito 93, en el año 1901, la descripción es mayor "El azúcar no es bueno para el estómago. Causa fermentación, y esto anubla la mente y trae mal humor". ${ }^{54}$ Relaciona otro peligro extremo de las costumbres babiló-

${ }^{53}$ Elena G. de White, Testimonios para la iglesia (Miami, FL: Asociación Publicadora Interamericana, 2003), 2:369-70.

${ }^{54}$ White, Consejos sobre el régimen alimenticio, 389. nicas, tomar refrescos con la comida. Ella describe la combinación del azúcar con la comida como un elemento perjudicial, especialmente para el que tiene problemas digestivos. Esta cita, de 1901, dice:

El azúcar no es buena para el estómago. Produce fermentación, y esto obnubila el cerebro y causa irritabilidad en la disposición de ánimo. Qué lástima que a menudo, cuando debería ejercerse la mayor abnegación, el estómago está lleno de una masa de alimento malsano, que permanece allí para descomponerse. La aflicción del estómago afecta el cerebro. El que come imprudentemente no se da cuenta de que se está descalificando para dar un consejo sabio, a fin de trazar planes para el mayor progreso de la obra de Dios. ${ }^{55}$

Finalmente, ella escribe, El azúcar recarga el organismo y estorba el trabajo de la máquina viviente. ${ }^{56}$ Otra carta de 1901, carta 37, dice: "Es bueno descartar el azúcar cuando se hacen galletitas. Algunos prefieren las galletitas más dulces,

${ }^{55}$ Ibíd.

${ }^{56}$ Ibíd. 
pero estas son perjudiciales para los órganos digestivos" ${ }^{57}$ Parece ser suficiente para que se entienda del daño que representa este ingrediente, que día a día es más procesado químicamente, incrementando su poder destructor en nuestra naturaleza también desgastada.

\section{No usar mucha sal}

La Review and Herald, del 29 julio de 1884, describe el principio: "No consumáis sal en gran escala”. ${ }^{58}$ En 1901, en la carta 37, ella reconoce que la sal es necesaria, pero no en gran cantidad, aunque reconoce que no sabe por qué.

Yo uso un poco de sal, y siempre lo hago, porque por la luz que Dios me ha dado, sé que este artículo en lugar de ser deletéreo es, en realidad, esencial para la sangre. No conozco cuál es la razón de este asunto, pero le doy la instrucción como me ha sido dada. ${ }^{59}$

A lado de la sal están los otros elementos que esconden la sal en sus preparados, aquellos que le

${ }^{57}$ Ibíd., 381.

${ }^{58}$ Ibíd., 505.

${ }^{59}$ Ibíd., 410 dan sabor, pero sin medir el uso de este elemento nocivo. Ella escribe, en 1905, "Evitese el uso de mucha sal y el de encurtidos y especias, consúmase mucha fruta y desaparecerá, en gran parte, la irritación que incita a beber mucho en la comida". ${ }^{60}$ Hoy se puede ver que en todos los productos que son dulces como los chocolates, dulces, galletas, etc., hay mucha sal. Al leer los ingredientes se verá que la mayor parte de productos, que son considerados dulces, contienen una gran cantidad de sal, siendo el motor de su uso, el lograr que el azúcar no hostigue el paladar. A este proceso se lo puede llamar "sal escondida".

\section{No tomar agua con los alimentos}

Otro sencillo principio de salud que, aunque parece fácil, tiene una fuerte raíz en las costumbres babilónicas. En 1890, ella escribió: "Cuanto más líquido se lleve al estómago con las comidas, tanto más difícil será la digestión de los alimentos; pues el líquido deberá ser primeramente absorbido" [C.T.B.H. 51] (1890) C.H. 119,

${ }^{60}$ White, Ministerio de curación, 235. 
120.61. La digestión pareciera ser el kit de la salud. Para mejorar nuestra salud, se tiene que corregir nuestro sistema digestivo. Esta cita es más amplia, unos años antes, 1884, un 29 de julio escribió:

"Muchos cometen un error al beber agua fría en sus comidas. Tomada con las comidas, el agua disminuye el flujo de las glándulas salivales; y cuanto más fría el agua, mayor es el perjuicio para el estómago. El agua o la limonada heladas, tomadas con la comida, detendrán la digestión hasta que el organismo haya impartido suficiente calor al estómago para habilitarlo a reiniciar su tarea. Las bebidas calientes son debilitantes y, además, los que complacen en usarlas llegan a ser esclavos del hábito. El alimento no debe ser lavado; no se necesita beber nada con los alimentos (R. \& H., julio 29 de 1884)". ${ }^{62}$

El agua es esencial para nuestra vida, hay que tomar abundante agua, pero fuera del tiempo de las comidas. La cita anterior se complementa con esta declaración hecha el mismo día, y publicada.

${ }^{61}$ White, Consejos sobre el régimen alimenticio, 126.

${ }^{62}$ Ibíd., 504.
Pero si algo se necesita para apagar la sed, el agua pura, bebida poco tiempo antes o después de la comida, es todo lo que la naturaleza exige. Nunca se tome té, café, cerveza, vino o cualquier bebida alcohólica. El agua es el mejor líquido posible para limpiar los tejidos. ${ }^{63}$

\section{Masticar bien los alimentos, no comer apurado}

Este principio de salud es bastante difícil de cumplir en Babilonia, en donde todo es correr y estrés. En 1890, en esa misma carta, que hablaba del agua y los alimentos, ella escribió: "Masticad con lentitud, permitiendo que la saliva se mezcle con los alimentos". ${ }^{64}$ El detalle de que el alimento permanezca buen tiempo en la boca traería muchos beneficios para la digestión. Esta misma cita se amplía:

"El beneficio que proviene del alimento no depende tanto de la cantidad de comida como de su completa digestión; y la satisfacción del gusto no depende tanto de la cantidad de alimentos inge-

\footnotetext{
${ }^{63}$ Ibíd.

${ }^{64}$ Ibíd., 126.
} 
ridos, como del tiempo que estos permanecen en la boca. Los que están en estado de excitación o ansiedad, o están apurados, harían bien en no comer hasta no encontrar descanso o alivio; porque las facultades vitales, ya severamente sobrecargadas, no pueden suplir los fluidos digestivos necesarios". ${ }^{65}$

\section{Evitar la mistura de comida}

Los famosos Bufet de Babilonia son anulados por una declaración sencilla. Bueno, estos lugares proveen toda una variedad de comidas, solo que hay que ser sabios para no mezclar muchos alimentos y solo limitarnos a pocos platos, ese mismo 29 de julio de 1884, ella escribe: "No tengáis una gran variedad en la misma comida. Tres o cuatro platos son suficientes". ${ }^{66}$ Ella lo grita diciendo que la variedad no está de acuerdo con los principios de la reforma prosalud.

Se lee así:

"Es necesario refrenar el apetito, comer lentamente, y solo de una variedad limitada en una misma

${ }^{65}$ Ibíd., 127.

${ }^{66}$ Ibíd., 130. comida. Esta instrucción necesita repetirse con frecuencia. No está de acuerdo con los principios de la reforma prosalud el tener tantos platos diferentes en la misma comida". ${ }^{67}$

\section{No postres con las comidas}

Al principio, ligado con el azúcar y la fermentación de los alimentos, se agrega este, en donde la mezcla de las verduras con los dulces es dañina. Esto incluye los refrescos y bebidas con azúcar (gaseosas, sodas, frugos, etc.). En 1900, en una carta numerada como la 142, ella escribe: "Los budines, los flanes, las tortas dulces y las verduras, todos servidos en la misma comida, causarán perturbación en el estómago". ${ }^{68}$ Inclusive, y eso también se dijo en cuanto al azúcar, diciendo que esta es más dañina que la carne, ella repite el principio en 1891, carta 10: "Pero el azúcar y la leche combinados tienen la tendencia a causar fermentación en el estómago y son así perjudiciales". ${ }^{69}$

\footnotetext{
${ }^{67}$ Ibíd., 127.

${ }^{68}$ Ibíd., 134.

${ }^{69}$ Ibíd., 138.
} 
La mezcla perfecta de los postres, el azúcar con la leche, según la luz que recibió, son muy perjudiciales, ella escribe en 1890: "Pero el azúcar y la leche combinados tienen la tendencia a causar fermentación en el estómago y son así perjudiciales". ${ }^{70}$ El problema de la fermentación pareciera que anula la buena digestión.

\section{No comer demasiado por la noche}

Este principio es contrario a los principios babilónicos de la alimentación. Los mejores lugares para comer abren sus puertas en las noches, esperando a sus clientes ignorantes. Ella escribió apuntando a un régimen de dos comidas, dice: "No debiera comer más que dos comidas por día. Si le parece necesario comer algo por la noche, beba un vaso de agua fría, y por la mañana se sentirá mucho mejor por no haber ingerido cosa alguna". ${ }^{71}$ Hay una declaración más amplia:

Es una costumbre común entre la gente del mundo comer tres

${ }^{70}$ Ibíd.

${ }^{71}$ Ibíd., 210. veces por día, además de ingerir alimentos a intervalos irregulares entre las comidas; y la última comida es generalmente la más pesada y se la ingiere a menudo antes de acostarse. Esto es invertir el orden natural, pues una comida copiosa no debe nunca ser ingerida tan tarde. Si estas personas cambiasen sus hábitos y comiesen solo dos veces por día, sin ingerir nada entre las comidas, ni siquiera una manzana, una nuez, ni fruta alguna, el resultado se vería en forma de un buen apetito y de un notable mejoramiento de la salud. ${ }^{72}$

Interesante el contenido inicial de esta cita, "entre la gente del mundo", es decir Babilonia, hay una costumbre peligrosa. Otra advertencia de este principio, declara: "es invertir el orden natural", es decir un principio ordenado por nuestro Creador es comer a la inversa de Babilonia. Increíblemente, ni aún las frutas entre comidas. Aún en las fiestas, este principio se rompe y pisotea, aparentemente, la voluntad de Dios; que nuestras fiestas sean inversas a las celebradas en el mundo.

${ }^{72}$ Elena G. White, Consejos sobre salud (Miami, FL: Asociación Publicadora Interamericana, 1989), 215-16. 
"El apetito se satisface sin medida en las fiestas de placer. A altas horas de la noche se sirven meriendas sazonadas y cenas compuestas de carnes condimentadas con salsas pesadas, pasteles, helados, te, café, etc. No es de sorprenderse que la gente que practica este tipo de alimentación sea de complexión pálida y sufra de trastornos digestivos". ${ }^{73}$

Pero hay una solución para las noches, comer más temprano pero algo muy liviano, ella escribe: "El pan retostado es bueno para la comida de la noche". ${ }^{74}$ Ella es bastante enérgica en este punto, en junio de 1878, en Health Reformer, escribe: "Los festines de glotones y los alimentos ingeridos en momentos inoportunos, dejan una influencia sobre cada fibra del organismo". ${ }^{75}$ Increíblemente menciona la influencia de inofensiva de una simple fiesta. A veces se piensa que una vez al año no hace daño, pero el principio es categórico. Lo lleva hasta lo sumo. La siguiente declaración lo dice:

${ }^{73}$ Ibíd., 110.

${ }^{74}$ White, Consejos sobre el régimen alimenticio, 273.

${ }^{75}$ Ibíd., 216.
"Esta es una costumbre sumamente perniciosa. Los animales, que no están dotados de razón y no saben nada acerca del recargo mental, pueden valerse de esta costumbre sin que les perjudique; pero estos no constituyen una norma para los seres racionales, que poseen facultades mentales que debieran usar para Dios y la humanidad. R. \& H., julio 29 de 1884". ${ }^{76}$

"Muchos comen a todas horas, sin tener en cuenta las leyes de la salud. Como resultado de esto, el intelecto se anubla. ¿Cómo pueden los hombres ser honrados con una iluminación divina cuando son tan precipitados en sus hábitos, tan desatentos a la luz que Dios les ha dado? Hermanos, ¿no es tiempo de convertiros en estos puntos importantes? (1892) G.W. 174 (edición antigua)".77

No ser intemperantes. Otro principio sencillo que contradice la voluntad de Babilonia, en donde los alimentos son consumidos en cada momento del día. El interés de White es que los padres comprendan este principio, les dice que sembrarían la semilla que

${ }^{76}$ Ibíd.

${ }^{77}$ Ibíd. 
produciría enfermedad y muerte. En 1870, en una reunión campestre, ella escribió: "El consumo de alimentos sencillos, no ingiriendo nada entre las comidas, no necesitan estar enfermos". ${ }^{78}$ Se puede leer las siguientes dos declaraciones que amplían lo dicho:

"Las madres, por su ejemplo, enseñan a sus hijos la intemperancia en el comer. Se les ha permitido comer casi en cualquier momento del día, lo cual mantiene siempre ocupado el sistema digestivo. Las madres han tenido poco tiempo para educar a sus hijos. Su tiempo valioso lo dedicaban a preparar comidas malsanas que luego colocaban sobre la mesa". ${ }^{79}$

"A los niños generalmente se les permite comer carnes, especias, mantequilla, queso, cerdo, pasteles suculentos y condimentos. También se les permite comer en forma irregular y entre comidas alimentos malsanos. Estas cosas hacen su obra de desarreglar el estómago, excitar los nervios a una acción antinatural y debili-

${ }^{78}$ Elena G. White, Joya de los testimonios (Nampa, ID: Pacific Press Publishing Association, 2004), 2:602.

${ }^{79}$ White, Consejos sobre el régimen alimenticio, 216. tar el intelecto. Los padres no se dan cuenta que están sembrando la semilla que producirá enfermedad y muerte". ${ }^{80}$

\section{Régimen de alimento sencillo}

Este principio va en contra del apetito pervertido de Babilonia. Ya desde 1875, Elena de White describe la lucha que se tendría con el apetito y las delicias de Babilonia. Ella lo describe como "la complacencia continua del apetito”, esta declaración es amplia y contiene información abundante:

"La Intemperancia comienza en de alimentos malsanos. Después de un tiempo, por la complacencia continua del apetito, los órganos digestivos se debilitan y el alimento ingerido no satisface. Se establecen condiciones malsanas y se anhela ingerir alimentos más estimulantes. El té, el café y la carne producen un efecto inmediato. Bajo la influencia de estos venenos el sistema nervioso se excita y, en algunos casos, el intelecto parece vigorizado momentáneamente y la imaginación resulta más vívida. Por el hecho de que estos estimulantes produ-

${ }^{80}$ Ibíd., 417. 
cen resultados pasajeros tan agradables, muchos piensan que los necesitan realmente y continúan consumiéndolos. Pero siempre hay una reacción. El sistema nervioso, habiendo sido estimulado indebidamente, obtuvo fuerzas de las reservas para su empleo inmediato.

Todo este pasajero fortalecimiento del organismo va seguido de una depresión. En la misma proporción, en que estos estimulantes vigorizan temporalmente el organismo, se producirá una pérdida de fuerzas de los órganos excitados después que el estímulo pasa. El apetito se acostumbra a desear algo más fuerte, lo cual tenderá a aumentar la sensación agradable, hasta que satisfacerlo llega a ser un hábito y continuamente se desean estimulantes más fuertes, como el tabaco, los vinos y licores. Cuanto más se complazca el apetito, tanto más frecuentes serán sus exigencias, y tanto más difícil será dominarlo. Cuanto más se debilite el organismo y menos pueda pasarlo sin estimulantes antinaturales, tanto más aumentará la pasión por esas cosas, hasta que la voluntad quede avasallada y no tenga ya fuerza para negarse a satisfacer el deseo malsano". ${ }^{81}$

${ }^{81}$ White, Joya de los testimonios, 1:97-8.
Elena de White es bastante fuerte con un hermano enfermo, y le reclama el volver a Dios, mejorando su alimentación. Si quizás parezca muy fuerte esta declaración, se debe recordar que es para alguien que está enfermo.

"Ud. necesita llevar a la práctica la reforma prosalud en su vida; negarse a sí mismo en el comer y beber para la gloria de Dios. Absténgase de los deseos carnales que batallan contra el alma. Necesita practicar la temperancia en todas las cosas. He aquí una cruz que Ud. ha rehuido. El conformarse a un régimen sencillo, que lo preserve en la mejor condición de salud, es la tarea que le corresponde. Si hubiera vivido de acuerdo con la luz que el cielo permitió que brillara en su sendero, mucho sufrimiento podría haberse ahorrado para su familia. Su propia conducta ha acarreado seguros resultados. Mientras continúe actuando de esta suerte, Dios no vendrá a su familia para bendecirlo en forma especial, y obrar un milagro a fin de ahorrar sufrimientos a su familia". ${ }^{82}$

"22Ibíd. 


\section{No frituras, no grasas}

Un principio más, tan simple, pero eficaz. Si comes frituras al final estarás frito. Esta frase puede resumir el principio de comer sin usar grasas saturadas.

"No creemos que las papas fritas sean saludables, porque se usa más o menos grasa o mantequilla para prepararlas. Las papas bien cocidas o hervidas, con crema y un poco de sal, son las más saludables. Las sobras de papas y batatas se preparan, con un poco de crema y sal, al horno y no fritas son excelentes". 83

Eliminar progresivamente leche, huevos y mantequilla

Este principio es para los días finales de la historia, para el tiempo del fin. Pero con qué se reemplaza la carne y sus derivados, ella escribe: "Convenientemente preparadas las aceitunas, lo mismo que las oleaginosas, pueden reemplazar la mantequilla y la carne". ${ }^{84}$ Hay que resaltar las palabras: "convenientemente preparadas". Esto quiere

${ }^{83}$ White, Consejos sobre el régimen alimenticio, 384.

${ }^{84}$ Ibíd., 416. decir: evitar la aceituna muy salada. Hay que cambiarle varias veces de agua para quitar la excesiva cantidad de sal.

"Enséñese a la gente a preparar alimentos sin mucho uso de leche o mantequilla. Expliquémosle que llegará pronto el tiempo en que será peligroso usar huevos, leche, crema o mantequilla, porque las enfermedades aumentan proporcionalmente a la maldad que reina entre los hombres. Se acerca el tiempo en que, debido a la iniquidad de la especie caída, toda la creación animal gemirá bajo las enfermedades que azotan nuestra tierra". 85

\section{Los niños no deben comer paste- les suculentos}

Este principio describe una vez más con dureza la influencia del azúcar, en donde ella preferiría comer carne antes que excesiva cantidad de azúcar. En 1891, en la Carta 10, ella manifiesta:

"Quisiera que todos fuéramos reformadores en pro de la salud. Me opongo al uso de pasteles. Estas mezclas no son saludables; nadie

${ }^{85}$ Ibíd., 415. 
puede tener buena capacidad digestiva y una mente clara si come mayormente masitas dulces y torta de crema y toda clase de pasteles, y consume una gran variedad de alimentos en una misma comida. Cuando hacemos esto, y luego tomamos frío, todo el sistema queda tan entorpecido y debilitado que no tiene poder de resistencia, no tiene fuerza para combatir la enfermedad. Preferiría un régimen con carne antes que las tortas y los pasteles dulces tan generalmente usados". 86

\section{No a los narcóticos, estimulantes y saborizantes}

Este principio parece el que ahora intentan usar algunos médicos contra el cáncer. Dios quería un pueblo alejado de este terrible mal. Desde 1899 ella pide alejarnos de la complacencia de los apetitos, pareciera decir que mientras más rico y exquisito es un plato, y complace nuestro apetito pervertido, más enfermedad y menos salud. Los peligros actuales, debido al incremento de la industria alimentaria, son descritos en las siguientes declaraciones:

${ }^{86}$ Ibíd., 398.
"Dios demanda de los padres que protejan a sus hijos contra la complacencia del apetito y especialmente contra el uso de estimulantes y narcóticos. Las mesas de los padres cristianos nunca debieran estar cargadas con alimentos que contienen condimentos y especias. Han de estudiar para preservar el estómago de cualquier abuso (Review and Herald. 27-6-1899)". 87

"Del comienzo al fin, el crimen del uso del tabaco y de la medicación con opio y drogas tiene su origen en el conocimiento pervertido. Miles y decenas de miles de vidas se pierden por el acto de tomar y comer el fruto venenoso, mediante las complicaciones de nombres que el común del pueblo no comprende. Están usando los productos venenosos que Satanás mismo ha plantado para que tomen el lugar del árbol de la vida, cuyas hojas eran para la sanidad de las naciones. (Manuscrito 119,1898$) " .88$

Hay que resaltar la frase: "complicaciones de nombres que

${ }^{87}$ Elena G. White, Conducción del niño (Nampa, ID: Pacific Press Publishing Association, 1964), 381.

${ }^{88}$ Elena G. White, La temperancia (Buenos Aires: Asociación Casa Editora Sudamericana, 1976), 66-7. 
el común del pueblo no comprende", porque allí está el sistema de alerta que pide Dios, para que el enemigo no nos introduzca el veneno de la enfermedad. Todo cristiano debe tener en cuenta los ingredientes que contiene cada alimento. Los nombres que el común del pueblo no comprende vienen en códigos como: E104, E110, E-236 (Ácido Fórmico el cual se emplea en quesos, bebidas dulces produce a largo plazo: cáncer), E102 (Tartrazina- Aumenta las alergias, el asma, produce hiperactividad o trastorno por déficit de atención con hiperactividad (TDAH) en niños), bromato, etc. Esta lista de aditivos para los alimentos incluye especialmente los cancerígenos, los bioperjudiciales y los que entrañan un grave riesgo para la salud. ${ }^{89}$ Por esta razón Elena de White, anticipándose al tiempo, alertó de los peligros que llegarían al final de los tiempos:

"Bajo el título de estimulantes y narcóticos se clasifica una gran

${ }^{89}$ "Guía práctica de aditivos alimentarios perjudiciales o nocivos", http:// www.e-aditivos.com/; "Aditivos Alimentarios", http://www.aditivos-alimentarios.com/2014/01/e407-carragenanos. html, (consultado: 15 de junio, 2014). variedad de sustancias que, aunque empleadas como alimento y bebida, irritan el estómago, envenenan la sangre y excitan los nervios. Su consumo es un mal positivo. Los hombres buscan la excitación de estimulantes, porque, por algunos momentos, producen sensaciones agradables. Pero siempre sobreviene la reacción. El uso de estimulantes antinaturales lleva siempre al exceso, y es un agente activo para provocar la degeneración y el decaimiento físico". 90

\section{Dormir temprano y siempre a una misma hora}

Finalmente, sin creer que sean estos los únicos principios, ella describe uno que será fundamental en la vida del cristiano, en 1870 ella escribió: "observan estrictamente la regularidad en las horas de dormir". ${ }^{91}$

\section{Conclusiones}

Aun cuando parezca que la alimentación no es un tema importante para la salvación del ser

${ }^{90}$ White, Consejos sobre el régimen alimenticio, 403.

${ }^{91}$ White, Joya de los testimonios, 2:602. 
humano, eso no es verdad. La evidencia bíblica estudiada es muy categórica, dejando claro que hay una conexión estrecha entre la alimentación o salud con nuestras inclinaciones pecaminosas. La gran cantidad de citas que se han revisado, consideradas como estatutos, no representa la totalidad de recomendaciones que da el Espíritu de Profecía, hay muchos detalles más. Sin embargo, aunque la mayoría son prohibiciones o invitan a la reflexión y el cambio de hábitos alimentarios, los resultados son positivos, imparten recomendaciones que traerán bendición en la vida del que lo aplica.

Satanás tiene la intención de embriagar al ser humano a través del apetito. Es su intención, a través de los alimentos, que se destruya los otros aspectos de la vida del ser humano. Por esta razón, el Señor pedía que los israelitas que no se contaminen con las maneras de vivir de las otras naciones, allí se entiende el celo de Dios, al establecer una cultura explícita para sus hijos. El profeta Ezequiel dijo: "Y si dijereis: ¿Por qué el hijo no llevará el pecado de su padre? Porque el hijo hizo según el derecho y la justicia, guardó todos mis estatutos y los cumplió, de cierto vivirá" (18:19). Este texto implica que un hijo que debería heredar todas las enfermedades (congénitas) de sus padres, si hace cambios radicales en el estilo de vida, no llevará la maldición de la enfermedad.

Dios promete levantar, en diferentes lugares, personas que han de profundizar estos temas, y que ayudarán al cuidado de su pueblo en la preparación de comida saludable. En 1902, ella escribió:

"Hay en muchos lugares personas a quienes el Señor comunicará ciertamente conocimiento acerca de cómo preparar alimentos sanos y apetitosos, si él ve que están dispuestas a usar con justicia este conocimiento. Los animales están enfermando cada vez más, y no transcurrirá mucho tiempo antes de que los alimentos de origen animal sean descartados por muchos, además de los adventistas del séptimo día. Se han de preparar alimentos sanos, capaces de sostener la vida, a fin de que hombres y mujeres no necesiten comer carne". ${ }^{92}$

"El Señor enseñará a muchos,

${ }^{92}$ White, Joya de los testimonios, 3:32. 
en todas partes del mundo, a combinar las frutas, los cereales y las verduras en alimentos que sostengan la vida y no comuniquen enfermedad. Personas que nunca han visto las recetas para hacer los alimentos sanos que ya están en venta, trabajarán con inteligencia, experimentarán con los productos alimenticios de la tierra, y recibirán información acerca del uso de estos productos. El Señor les mostrará lo que deben hacer". ${ }^{93}$

Se entiende que, en estos tiempos finales de la historia, Dios está dispuesto a seguir guiando a sus hijos en la búsqueda de salud. El mundo parece un hospital lleno de víctimas de enfermedades físicas y espirituales, y necesita de un ejército de reformadores de la salud. Lo triste es que muchos, en lugar de reaccionar en forma animada a estas recomendaciones, preferirán vivir en el estado normal de las cosas, entonces los juicios destinados para Babilonia también caerán sobre ellos. Se espera no estar en este grupo, pero todo dependerá de las decisiones que, bajo la dirección de Dios, todo buen cristiano debe tomar.

Pero, ¿como evitar estas consecuencias? "El fin de todo el discurso oído es este: Teme a Dios, y guarda sus mandamientos; porque esto es el todo del hombre. Porque Dios traerá toda obra a juicio, juntamente con toda cosa encubierta, sea buena o sea mala". (Ecl 12:13-14).

${ }^{93}$ Ibíd. 